\title{
GAMBARAN PENGETAHUAN TENTANG HALITOSIS PADA BURUH DI PELABUHAN MANADO
}

\author{
${ }^{1}$ Rizkia Irianti \\ ${ }^{2}$ Karel Pandelaki \\ ${ }^{3}$ Christy Mintjelungan
}

\author{
${ }^{1}$ Kandidat Skripsi Program Studi Pendidikan Dokter Gigi Fakultas Kedokteran Universitas \\ Sam Ratulangi \\ ${ }^{2}$ Bagian Ilmu Penyakit Dalam Fakultas Kedokteran Universitas Sam Ratulangi \\ ${ }^{3}$ Program Studi Pendidikan Dokter Gigi Fakultas Kedokteran \\ Universitas Sam Ratulangi Manado \\ Email: rizkiairiantidjafar@gmail.com
}

\begin{abstract}
Halitosis is a general term used to describe bad breath odor emanating from the oral cavity that may occur in physiological and pathological. The cause of halitosis much comes from the mouth as much as $80 \%$. People's knowledge of halitosis is needed because it can help to prevent and deal with the halitosis and may be the first step for further diagnosis of the systemic disease. This study aims to describe the knowledge of halitosis in labor at the port of Manado. This research is a descriptive study using cross-sectional approach. The sample size was obtained by using Slovin formula with a total sample obtained 77 samples and sampling techniques using simple random sampling by means of a lottery. Knowledge was measured using a questionnaire containing some questions about the causes and prevention of halitosis. The result is a total of 27 respondents who have a good knowledge, 39 respondents have sufficient knowledge and 11 respondents have less knowledge. Respondents aged 37-48 years is the most respondents had a good knowledge. Based on this study, suggested a good enough knowledge to be maintained and applied in order to maintain and improve the health of your teeth and mouth.
\end{abstract}

Keywords: Halitosis, knowledge, stevedore.

\begin{abstract}
Abstrak: Halitosis adalah suatu istilah umum yang digunakan untuk menjelaskan bau nafas tidak sedap yang berasal dari rongga mulut yang dapat terjadi secara fisiologis dan patologis. Penyebab halitosis paling banyak berasal dari dalam mulut sebanyak $80 \%$. Pengetahuan masyarakat terhadap halitosis sangat dibutuhkan karena dapat membantu untuk mencegah dan menanggulangi halitosis serta dapat menjadi langkah awal untuk mendiagnosis lebih lanjut terhadap penyakit sistemik.Penelitian ini bertujuan untuk mengetahui gambaran pengetahuan tentang halitosis pada buruh di pelabuhan Manado. Penelitian ini merupakan penelitian deskriptif dengan menggunakan pendekatan potong lintang. Ukuran sampel diperoleh dengan menggunakan rumus Slovin dengan total sampel yang didapatkan 77 sampel dan teknik pengambilan sampel menggunakan simple random sampling dengan cara lotre. Pengetahuan diukur dengan menggunakan kuesioner yang berisi beberapa pertanyaan tentang penyebab dan pencegahan halitosis. Hasilnya ialah sebanyak 27 responden yang mempunyai pengetahuan baik, 39 responden mempunyai pengetahuan cukup dan 11 responden mempunyai pengetahuan kurang. Responden berusia 37-48 tahun ialah responden paling banyak mempunyai pengetahuan baik. Berdasarkan penelitian ini, pengetahuan yang cukup baik disarankan untuk dapat dipertahankan dan diaplikasikan guna mempertahankan dan meningkatkan derajat kesehatan gigi dan mulut.
\end{abstract}

Kata Kunci : Halitosis, pengetahuan, buruh pelabuhan. 
Halitosis disebut juga dengan fetor ex ore, fetor oris atau oral malodor merupakan istilah umum untuk menunjukkan bau nafas yang tidak sedap, ${ }^{1}$ penyebabnya dapat berasal dari rongga mulut dan diluar rongga mulut yang mempunyai komplikasi kesehatan dan sosial. ${ }^{2}$ Penyebab halitosis paling banyak berasal dari rongga mulut, yaitu sekitar 80-90\%. Halitosis yang berasal dari luar rongga mulut terjadi hanya sedikit yaitu sekitar 10-20\%.

Prevalensi penderita halitosis disetiap negara berbeda - beda. Prevalensi penderita halitosis di China mencapai $27,5 \%$ dengan sampel sebanyak 2500 orang. ${ }^{4}$ Penelitian yang dilakukan di Amerika menunjukkan bahwa prevalensi penderita halitosis cukup tinggi yaitu mencapai $50 \%$ dari jumlah populasi di Amerika. $^{3}$ Menurut American Dental Association (ADA), bau mulut merupakan masalah utama setelah karies dan penyakit periodontal yang dikeluhkan oleh masyarakat di Amerika. ${ }^{4}$

Penyebab ekstraoral dari halitosis antara penyakit sistemik seperti diabetes melitus, penyakit pada sistem respiratorius atau gastrointestinal, gagal organ hepar dan gangguan metabolik. ${ }^{5.6}$ Pada halitosis ekstraoral, substansi penyebab dalam saluran gastrointestinal sebanyak $90 \%$ ialah asam lemak (asam asetat, asam propionik dan asam butirat), amoniak $6,5 \%$ dan sisanya ialah komponen Sulfur (hidrogen sulfida, dan metil merkaptan) dan komponen nitrogen (indol, skatol, piridin, pirol, amonia, trimetilamin). ${ }^{7}$

Pengetahuan tentang halitosis merupakan hal yang penting karena dapat membantu untuk mencegah dan menanggulangi halitosis serta dapat menjadi langkah awal untuk mendiagnosis lebih lanjut terhadap penyakit sistemik. Pengetahuan berhubungan langsung dengan tingkat pendidikan, semakin tinggi pendidikan seseorang maka pengetahuan yang didapat akan semakin banyak. Jakarta Anti Halitosis Centre telah dibentuk di Indonesia namun penyuluhan tentang halitosis masih sangat kurang, dalam hal ini sebenarnya penting untuk meningkatkan kesadaran terhadap kesehatan gigi dan mulut.

Buruh di pelabuhan Manado merupakan pekerja yang terdaftar di Kantor Kesyahbandaran dan Otoritas Pelabuhan yang masih membutuhkan pengetahuan tentang kesehatan gigi dan mulut, karena kurangnya penyuluhan kesehatan gigi dan mulut terutama halitosis. Pentingnya interaksi sosial sehingga peneliti tertarik untuk meneliti gambaran pengetahuan tentang halitosis pada buruh di pelabuhan Manado.

\section{METODE PENELITIAN}

Penelitian ini merupakan penelitian deskriptif dengan menggunakan pendekatan potong lintang (cross sectional study) dilaksanakan di pelabuhan kota Manado pada bulan Agustus 2014. Populasi dalam penelitian ini yaitu seluruh pria dewasa yang bekerja sebagai buruh di pelabuhan Manado. Menurut survei awal berjumlah 332 orang. Untuk mendapatkan besar minimal sampel yang akan diambil dalam penilitian ini diperoleh dengan menggunakan rumus Slovin, yaitu sebesar 77 orang. Teknik pengambilan sampel yang digunakan ialah Simple Random Sampling dengan cara lotre, dimana sampel diambil berdasarkan kriteria inklusi dan eksklusi yang telah ditetapkan.

Kriteria inklusi yaitu berusia 25-60 tahun, dapat berkomunikasi dengan baik, dan bersedia mengikuti penelitian. Sedangkan kriteria ekslusi yaitu buruh dengan kondisi fisik dan psikologi yang tidak memungkinkan untuk dijadikan sampel penelitian. Penelitian ini diawali dengan adanya surat pengantar permohonan izin penelitian yang diperoleh dari Program Studi Pendidikan Dokter Gigi, kemudian penelitian dimulai setelah dikeluarkannya izin dari pihak Kantor Kesyahbandaran dan Otoritas Pelabuhan Manado. Responden yang menjadi subjek penelitian, dimintai untuk menandatangani informed consent, wawancara yang dilakukan dengan menggunakan kuesioner. Penelitian ini dilakukan dengan menggunakan data primer yaitu data 
diperoleh secara langsung dari responden melalui wawancara menggunakan kuesioner. Data yang diperoleh, dikumpulkan kemudian diolah dan dianalisis secara manual berdasarkan persentase dan disajikan dalam bentuk tabel distribusi frekuensi.

Untuk mengukur pengetahuan pada buruh digunakan 10 pertanyaan, dalam bentuk pertanyaan tertutup. Setiap pertanyaan diberi skor 1 untuk jawaban tahu dan 0 untuk jawaban tidak tahu. Setelah kuesioner dinilai, maka tingkat pengetahuan dikelompokkan berdasarkan kategori tersebut: ${ }^{8}$

1. Pengetahuan baik (total skor 8-10)

2. Pengetahuan sedang (total skor 4-7)

3. Pengetahuan kurang (total skor 0-3)

\section{HASIL PENELITIAN}

Karakteristik subjek penelitian di distribusikan berdasarkan kelompok umur dan tingkat pendidikan. Distribusi subjek penelitian berdasarkan kelompok umur dapat dilihat dari tabel 1. Karakteristik umur responden pada penelitian ini dibagi menjadi 3 kelompok umur. Responden paling banyak terdapat pada kelompok umur 37 - 48 tahun dan 49 - 60 tahun berjumlah sama sebanyak 28 responden $(36,4 \%)$ pada setiap kelompok umur.

Distribusi responden berdasarkan tingkat pendidikan dapat dilihat pada table.

Karakteristik tingkat pendidikan berdasarkan pendidikan terakhir yang ditempuh oleh responden sendiri. Responden dengan tingkat pendidikan SD sebanyak 36 responden $(46,8 \%)$, jumlah responden dengan tingkat pendidikan SMP atau sederajat ialah 24 responden $(31,2 \%)$, jumlah responden dengan pendidikan SMA atau sederajat sebanyak 17 responden $(22,0 \%)$

Distribusi pengetahuan responden secara keseluruhan pada tabel 3, pengetahuan secara keseluruhan ini ialah gambaran dari pengetahuan yang dimiliki buruh di pelabuhan Manado. Yang paling banyak adalah berpengetahuan sedang berjumlah sebanyak 39 responden $(50,6 \%)$, 27 responden $(35,1 \%)$ mempunyai pengetahuan baik dan sisanya 11 responden $(14,3 \%)$ yang mempunyai pengetahuan kurang.

Distribusi pengetahuan tentang halitosis pada tabel 4, pengetahuan responden dalam penelitian ini diuji dengan kuesioner yang terdiri dari 10 pertanyaan. Berdasarkan distribusi jawaban responden pada 10 nomor dalam kuesioner, dapat dilihat bahwa pertanyaan paling banyak dijawab tahu oleh responden ialah pertanyaan mengenai halitosis karena sisa makanan yang tidak dibersihkan dengan jumlah jawaban tahu sebanyak 85,7\%. Jawaban yang paling sedikit dijawab tahu ialah pertanyaan mengenai halitosis pada penderita ginjal menahun dengan jawaban tahu sebanyak $31,1 \%$.

Tabel 1. Distribusi subjek penelitian berdasarkan kelompok umur

\begin{tabular}{ccc}
\hline $\begin{array}{c}\text { Umur } \\
\text { (Tahun) }\end{array}$ & Jumlah & $(\%)$ \\
\hline $25-36$ & 21 & 27,2 \\
$37-48$ & 28 & 36,4 \\
$49-60$ & 28 & 36,4 \\
\hline Jumlah & 77 & 100 \\
\hline
\end{tabular}

Tabel 2. Distribusi responden berdasarkan tingkat pendidikan.

\begin{tabular}{ccc}
\hline $\begin{array}{c}\text { Tingkat } \\
\text { Pengetahuan }\end{array}$ & Jumlah & $\%$ \\
\hline Baik & 27 & 35,1 \\
Sedang & 39 & 50,6 \\
Kurang & 11 & 14,3 \\
\hline Jumlah & 77 & 100 \\
\hline
\end{tabular}

Tabel 3. Pengetahuan responden secara keseluruhan.

\begin{tabular}{ccc}
\hline $\begin{array}{c}\text { Pendidikan } \\
\text { Terakhir }\end{array}$ & Jumlah & $(\%)$ \\
\hline SD & 36 & 46,8 \\
SMP & 24 & 31,2 \\
SMA & 17 & 22,0 \\
\hline Jumlah & 77 & 100 \\
\hline
\end{tabular}


Tabel 4. Tabel distribusi pengetahuan tentang halitosis

\begin{tabular}{|c|c|c|c|c|c|c|}
\hline \multirow{3}{*}{ Pertanyaan } & \multicolumn{6}{|c|}{ Pengetahuan Responden } \\
\hline & \multicolumn{2}{|c|}{ Tahu } & \multicolumn{2}{|c|}{ Tidak Tahu } & \multirow{2}{*}{$\frac{\text { Jumlah }}{\mathrm{n}}$} & \multirow{2}{*}{$\begin{array}{c}\text { Persentase } \\
\%\end{array}$} \\
\hline & $\mathrm{n}$ & $\%$ & $\mathrm{n}$ & $\%$ & & \\
\hline $\begin{array}{l}\text { Rokok dan } \\
\text { alkohol }\end{array}$ & 60 & 77,9 & 17 & 22,1 & 77 & 100 \\
\hline - Obat & 26 & 33,8 & 51 & 66,2 & 77 & 100 \\
\hline $\begin{array}{l}\text { - Sisa makanan } \\
\text { yang tidak } \\
\text { dibersihkan }\end{array}$ & 66 & 85,7 & 11 & 14,3 & 77 & 100 \\
\hline $\begin{array}{l}\text { Gigi yang } \\
\text { berlubang }\end{array}$ & 62 & 80,6 & 15 & 19,4 & 77 & 100 \\
\hline $\begin{array}{l}\text { - Penyakit } \\
\text { ginjal } \\
\text { menahun }\end{array}$ & 24 & 31,1 & 53 & 68,9 & 77 & 100 \\
\hline $\begin{array}{l}\text { Penyakit pada } \\
\text { paru dan } \\
\text { hidung }\end{array}$ & 45 & 58,4 & 32 & 41,6 & 77 & 100 \\
\hline - Penyakit hati & 27 & 35,1 & 50 & 64,9 & 77 & 100 \\
\hline - Obat kumur & 62 & 80,6 & 15 & 19,4 & 77 & 100 \\
\hline - Air putih & 54 & 70,1 & 23 & 29,9 & 77 & 100 \\
\hline $\begin{array}{l}\text { - } \quad \text { Sikat gigi } \\
\text { secara teratur }\end{array}$ & 62 & 82,6 & 15 & 19,4 & 77 & 100 \\
\hline
\end{tabular}

Tabel 5. Distribusi frekuensi pengetahuan responden berdasarkan umur

\begin{tabular}{ccccccccc}
\hline \multirow{2}{*}{ Umur } & \multicolumn{8}{c}{ Tingkat Pengetahuan } \\
\cline { 2 - 9 } (tahun) & \multicolumn{2}{c}{ Baik } & \multicolumn{2}{c}{ Sedang } & Kurang & Jumlah & Persentase \\
\cline { 2 - 9 } & $\mathrm{n}$ & $\%$ & $\mathrm{n}$ & $\%$ & $\mathrm{n}$ & $\%$ & $\mathrm{n}$ & $\%$ \\
\hline $25-36$ & 8 & 38,1 & 12 & 57,1 & 1 & 4,8 & 21 & 100 \\
$37-48$ & 11 & 28,6 & 12 & 42,9 & 5 & 17,8 & 28 & 100 \\
$49-60$ & 8 & 39,3 & 15 & 53,6 & 5 & 17,8 & 28 & 100 \\
\end{tabular}


Tabel 6. Distribusi frekuensi pengetahuan responden berdasarkan tingkat pendidikan

\begin{tabular}{|c|c|c|c|c|c|c|c|c|}
\hline \multirow{3}{*}{ Pendidikan } & \multicolumn{8}{|c|}{ Tingkat pengetahuan } \\
\hline & \multicolumn{2}{|c|}{ Baik } & \multicolumn{2}{|c|}{ Sedang } & \multicolumn{2}{|c|}{ Kurang } & \multirow{2}{*}{$\begin{array}{c}\text { Jumlah } \\
\mathrm{n}\end{array}$} & \multirow{2}{*}{$\begin{array}{c}\text { Persentase } \\
\%\end{array}$} \\
\hline & $\mathrm{n}$ & $\%$ & $\mathrm{n}$ & $\%$ & $\mathrm{n}$ & $\%$ & & \\
\hline SD & 13 & 36,1 & 19 & 52,8 & 4 & 11,1 & 36 & 100 \\
\hline SMP & 6 & 25 & 14 & 58,3 & 4 & 16,7 & 24 & 100 \\
\hline SMA & 8 & 47,0 & 6 & 35,3 & 3 & 17,7 & 17 & 100 \\
\hline
\end{tabular}

Distribusi frekuensi pengetahuan responden berdasarkan umur, responden berusia 25-36 tahun yang mempunyai pengetahuan baik sebanyak 8 responden $(38,1 \%)$, pengetahuan sedang sebanyak 12 responden $(57,1 \%)$ dan pengetahuan kurang sebanyak 1 responden $(4,8 \%)$. Pengetahuan baik paling banyak terdapat pada responden berusia 37-48 tahun sebanyak 11 responden $(39,3 \%)$, pengetahuan sedang sebanyak 12 responden $(42,9 \%)$ dan pengetahuan kurang sebanyak 5 responden $(17,8 \%)$. Responden berusia 49-60 tahun yang mempunyai pengetahuan baik sebanyak 8 responden $(28,6 \%)$, pengetahuan sedang sebanyak 15 responden $(53,6 \%)$ dan pengetahuan kurang sebanyak 5 responden $(17,8 \%)$.

Distribusi frekuensi pengetahuan responden berdasarkan tingkat pendidikan, responden dengan tingkat pendidikan terakhir SD yang mempunyai pengetahuan baik sebanyak 13 responden $(36,1 \%)$, pengetahuan sedang sebanyak 19 responden $(52,8 \%)$ dan pengetahuan kurang sebanyak 4 responden $(11,1 \%)$. Responden dengan tingkat pendidikan terakhir SMP/sederajat yang mempunyai pengetahuan baik sebanyak 6 responden (25\%), pengetahuan sedang sebanyak 14 responden $(58,3 \%)$ dan pengetahuan kurang sebanyak 4 responden $(16,7 \%)$. Responden dengan tingkat pendidikan terakhir SMA/sederajat yang mempunyai pengetahuan baik sebanyak 8 responden $(47,0 \%)$, pengetahuan sedang sebanyak 6 responden $(35,3 \%)$, dan pengetahuan kurang sebanyak 3 responden $(17,7 \%)$.

\section{BAHASAN}

Penelitian ini diikuti oleh buruh yang bekerja di pelabuhan Manado yang berjumlah sebanyak 77 responden yang tiap kelompok umur hampir sama banyak namun pada pembagian karakteristik responden menurut tingkat pendidikan terakhir, responden dengan tingkat pendidikan terakhir SMA/sederajat merupakan responden paling sedikit.

Berdasarkan hasil penelitian pengetahuan secara keseluruhan, responden paling banyak mempunyai pengetahuan yang sedang yaitu sebanyak 39 responden $(50,7 \%)$, pengetahuan baik mempunyai jumlah 27 responden $(35 \%)$ dan pengetahuan kurang hanya mempunyai responden sejumlah 11 responden $(14,3 \%)$.

Buruh di pelabuhan Manado sangat sering melakukan interaksi sosial baik di dalam maupun di luar pelabuhan, sehingga memungkinkan didapatkan lebih banyak informasi tentang halitosis. Selain itu para buruh juga mendapatkan setiap informasi dari media audio maupun visual. Menurut peneliti, 
hal inilah yang memengaruhi pengetahuan pada buruh yang tergolong sedang.

Sebagian besar responden yang mempunyai pengetahuan baik ialah responden yang berusia 37-48 tahun yaitu sebanyak 11 responden $(39,3 \%)$ diikuti responden berusia 25-36 dan 49-60 tahun yang mempunyai jumlah yang sama sebanyak 8 responden $(38,1 \%)$. Penelitian di Minahasa menunjukkan bahwa responden dengan umur 20-50 tahun merupakan responden yang sudah lebih banyak mendapatkan informasi seiring dengan semakin lama interaksinya dengan orang lain dilingkungannnya. ${ }^{8}$

Ditinjau dari jumlah keseluruhan responden dengan pendidikan terakhir SMA/sederajat mempunyai jumlah responden paling banyak pada kategori pengetahuan baik yaitu sebanyak 8 responden $(47,0 \%)$ dari 17 responden, diikuti oleh tingkat pendidikan terakhir SMP/sederajat dengan 6 responden $(25 \%)$ dari 24 responden, tingkat pendidikan SD dengan 13 responden $(36,1 \%)$ dari 36 responden.

Penelitian ini diikuti oleh 17 responden $(100 \%)$ yang tingkat pendidikan terakhirnya SMA/sederajat, 8 responden $(47,0 \%)$ diantaranya mempunyai pengetahuan baik, 6 responden $(35,3 \%)$ mempunyai pengetahuan sedang dan hanya 3 responden $(17,7 \%)$ yang mempunyai pengetahuan kurang.

Responden dengan tingkat pendidikan terakhir SMP/sederajat yang mengikuti penelitian ini sebanyak 24 responden (100\%). Responden yang tingkat pendidikan terakhir ini paling banyak tergolong dalam oengetahuan sedang yaitu sebanyak 14 responden $(58,3 \%)$ sedangkan responden dengan pengetahuan kurang hanya 4 responden $(16,7 \%)$.

Tingkat pendidikan terakhir SD pada penelitian ini diikuti oleh 36 responden (100\%). Responden paling banyak mempunyai pengetahuan sedang yaitu sebanyak 19 responden (52,8\%), pengetahuan baik sebanyak 13 responden $(36,1 \%)$ dan pengetahuan kurang hanya 4 responden $(11,1 \%)$.

Berdasarkan data tersebut dapat dilihat bahwa tingkat pendidikan terakhir responden dapat memengaruhi pengetahuan tentang halitosis. Responden mendapatkan informasi dari pendidikan formal yang menambah pengetahuan terhadap kehidupannya serta interaksi sosial dan mendapat pesan dari media yang memungkinkan lebih banyak mendapatkan informasi. Selain itu, responden juga mempunyai pengetahuan baik dan sedang karena pengetahuan tentang halitosis bisa diketahui responden berdasarkan pengalaman sehari-hari.

Pengetahuan tentang halitosis ialah hasil dari tahu suatu keadaan yang berhubungan dengan bau mulut yang berasal dari rongga mulut, yakni setelah seseorang melakukan penginderaan terhadap halitosis.

\section{SIMPULAN}

1. Sebagian besar pengetahuan tentang halitosis pada buruh di pelabuhan Manado mempunyai kategori sedang.

2. Berdasarkan tingkat pendidikan yang mempunyai pengetahuan baik paling banyak ialah pendidikan terakhir Sekolah Menengah Atas (SMA)

\section{SARAN}

1. Bagi buruh pelabuhan diharapkan dapat megunjungi dokter gigi sekurangkurangnya enam bulan sekali.

2. Bagi instansi kesehatan agar lebih meningkatkan kegiatan penyuluhan tentang kesehatan gigi dan mulut khususnya halitosis agar cepat dalam penanganan dan tidak terjadi hal-hal yang tidak diinginkan.

3. Mahasiswa dapat mengembangkan penelitian ini dengan menghubungkan pengetahuan terhadap halitosis dengan kebiasaan (habit) maupun oral hygiene yang dimiliki responden.

4. Dapat dilakukan penelitian lebih lanjut. 
DAFTAR PUSTAKA

1. Burton JP, Chilcott CN, Tagg JR. The rationale and potential for the reduction of oral malodour using Streptococcus salivarius probiotics. Oral Dis 2005;11(Suppl. 1):29-31.

2. Cortelli JR, Barbosa MDS, Westphal MA. Halitosis: a review of associated factors and therapeutic approach. Braz Oral Res 2008;1(1):44-54

3. Almas K, Al-Hawish A. Oral hygiene Practices. Smoking habits and self perceived oral malodor among dental student. The Journal of Comtemporary Dental Practice 2003:4(4):077-090.

4. Youngnak PP, Vachirarojpisan $T$. Prevalence of self perceived oral malodor in a group of thai dental patients. Journal of dentistry: Tehran Dentistry of Medical Science
2010:7(4)196-204.

5. Murata T, Fujiyama Y, Yamaga T, Miyazaki H. Breath malodor in an asthmatic patients caused by side-effects of medication: a case report and review of the literature. J Oral Dis 2003;9:2736.

6. Mitchell SC. Trimethylaminuria (fish-odour syndrome) and oral malodour. J Oral Dis 2005;11(Suppl 1):10-3.

7. Sato H, Hirose T, Kimura T, Moriyama $Y$, Nakashima Y. Analysis of malodorous volatile substances of human waste: feces and urine. $J$ Health Sci 2001;47(5):483-90

8. Saerang P. Pengetahuan Masyarakat Watuliney Indah terhadap Halitosis. [Skripsi] Manado: Fakultas Kedokteran Universitas Sam Ratulangi; 2012. 